\title{
2||-||||||||||||||||||||||||||||||||||||||||||||||||||||||||||||||'.
}

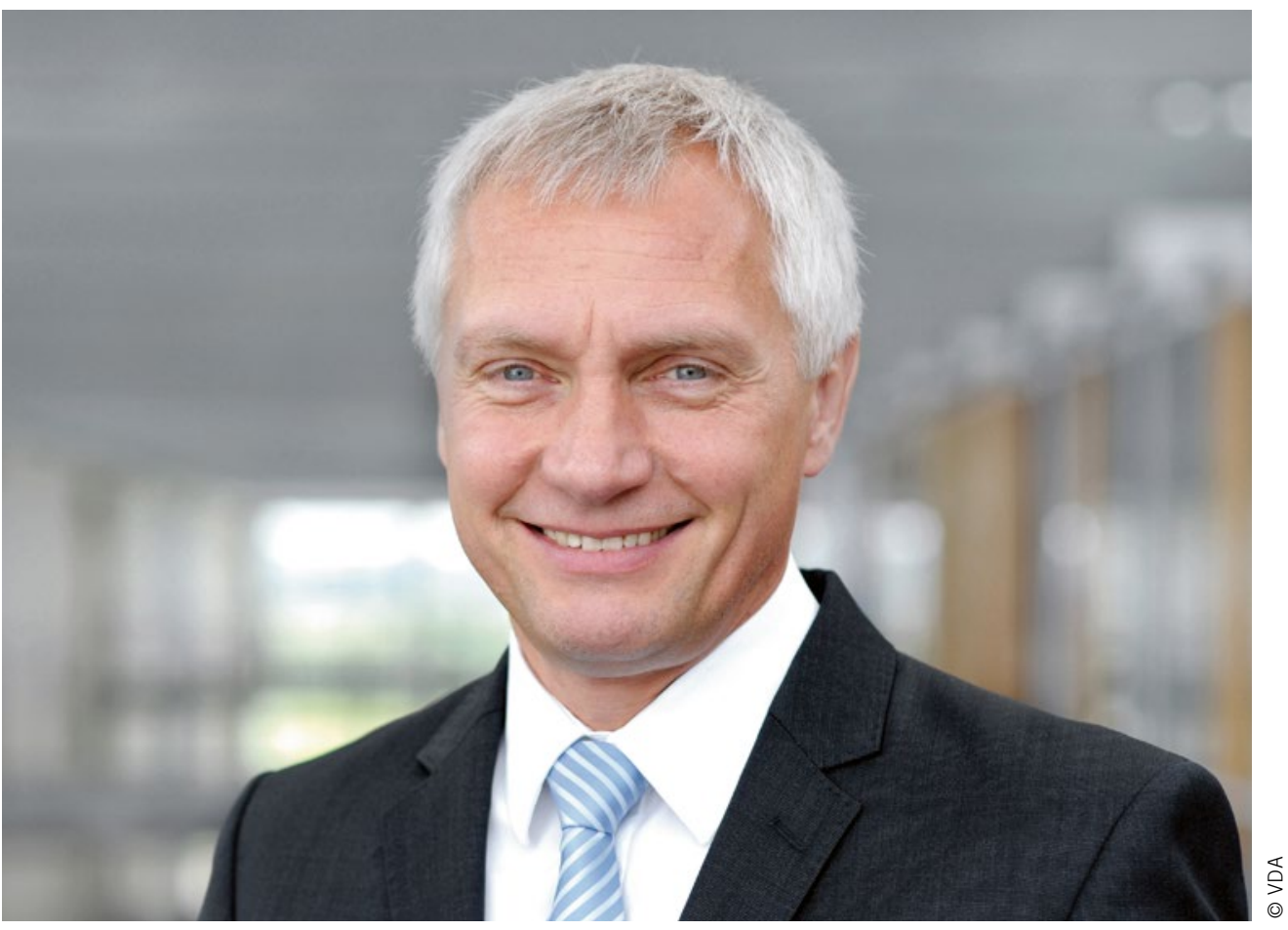

Dr. Joachim Damasky

Managing Director, German Association of the Automotive Industry (VDA), and Managing Director of the Research Association of Automotive Technology (FAT), Member of the ATZ Advisory Board

\section{Greater Safety, Efficiency and Comfort}

Networked, autonomous driving, alongside new powertrain technologies, is the most important area of development in the automotive industry. The aim is to make individual mobility more efficient, more comfortable and, most importantly, safer, because human error is responsible for more than $90 \%$ of road accidents. Connectivity and self-driving cars will eliminate many of the causes of accidents. Cars that can perform a number of driving manoeuvres independently can also assess whether drivers are behaving safely and inform them that there is a stationary queue of traffic or a moving object ahead or that they are driving too fast. In addition, electronic systems will improve traffic flows, which in turn will reduce fuel consumption and cut emissions.

We are currently in a phase where driver assistance systems are turning into partially automated driving functions that help drivers in difficult or boring situations, such as stopstart traffic, jams, monotonous motorway journeys with speed limits, keeping a suitable distance from the car in front, sudden braking, parking in confusing multi-storey car parks, changing lanes or turning off. The assistance systems become involved in precisely the situations where many accidents occur.

It is not only car manufacturers that are working in this area. The commercial vehicle industry is also playing a pioneering role in improving road safety. Automatic gearboxes and elec- tronic and emergency braking systems are just some of the technologies first used in commercial vehicles before they became optional extras for cars.

Because of the long distances they cover (more than $100,000 \mathrm{~km}$ per year), commercial vehicles are ideal candidates for autonomous driving. In addition, efficiency is an even more important factor in trucks than in cars. The crucial question is how much fuel is needed to transport $1 \mathrm{t}$ of goods over a distance of $100 \mathrm{~km}$. Even small savings add up to a considerable amount over long distances.

Only recently, truck manufacturers carried out a major cross-border test of platooning as part of the European Truck Challenge. This consists of a fully networked convoy of trucks with the first truck setting the speed and the others following closely in its slipstream. The $66^{\text {th }}$ IAA Commercial Vehicles in Hanover in Germany demonstrated how close the commercial vehicle industry has come to the vision of automated trucks. A wide range of innovations that will make goods transport and mobility more efficient, greener, smarter and even safer were on display at the show this year as part of the "New World Mobility Logistics" format.

One thing is clear. In order to make our roads safer, allow traffic to flow more smoothly and further reduce emissions, we need the new digital technologies. They also offer us the opportunity to transport goods and people more efficiently. 